\title{
Para Arzının Belirlenmesinde Post Keynesyenler Arasındaki Temel Ayrılıklar: Uyumcular ve Yapisalcilar
}

\section{Fundamental Differences Between Post Keynesians in Determining Money Supply: Accommodationists and Structuralists}

Dicle Özdemir ${ }^{\mathrm{a}^{*}}$

${ }^{a}$ Dr. Öğr. Üyesi, Muğla Sttkı Koçman Üniversitesi, İIBF İktisat Bölümü, Muğla/Türkiye. ORCID: 0000-0002-7594-1054

\section{MAKALE BİGİSI \\ Makale Geçmişi: \\ Başvuru tarihi: 24 Mayıs 2018 \\ Düzeltme tarihi: 06 Ocak 2019 \\ Kabul tarihi: 13 Şubat 2019}

\section{Anahtar Kelimeler:}

Para arz1

İçsel Para

Post Keynesyen

Minsky

Uyumcular

Yapısalcilar

\section{A R T I CLE INFO}

\section{Article history:}

Received 24 May 2018

Received in revised 06 January 2019

Accepted 13 February 2019

\section{Keywords:}

Money supply

Endogenous Money

Post Keynesian

Minsky

Horizontalists

Structuralists
ÖZ

Para arz eğrisinin eğimi ve paranın içselliği ile likidite tercihi teorisi arasındaki bağlantı Post Keynesyenler arasında önemli bir tartı̧̧ma konusudur. Gerek uyumcu Post Keynesyen yaklaşım gerekse yapısalcı Post Keynesyen yaklaşım banka kredisini para ile eş değer olarak görseler de kredi arzının tamamen ya da kısmen kredi talebi ile belirlenip belirlenmediği hakkında farklı görüşlere sahiptirler. Daha da önemlisi paranın içselliği konusunda yapısalcıların "banka kredisi" ve uyumcuların "kredi parası" şeklinde şeklinde farklı tamımlama durumu da söz konusudur. $\mathrm{Bu}$ çalışmada söz konusu Post Keynesyen teorinin iki ana kolunu oluşturan uyumcular ve yapısalcılar arasındaki paranın içselliğine istinaden ortaya çıkan görüş ayrılıklarının temeli tartışılacak ve söz konusu ayrışma, likidite tercihi ve kaldıraçlı kredileri finansal istikrarsızlıkların ana nedeni olarak gören Minsky’nin finansal istikrarsızlık hipotezi açısından yeniden incelenecektir.

\begin{abstract}
A B S T R ACT
The relationship between the slope of the money supply curve, the endogeneity of the money and the liquidity preference theory leads to a significant debate among the Post Keynesians. Even though both the accommodationists and the structuralists accept bank credit as equivalent to money, they do not agree with the assumption that the credit supply is determined in whole or in part by credit demand. More importantly, with regard to the concept of endogeneity of money, there are also different explanations in the form of "bank loan" as defined by the structuralists or "loan money" made by the accommodationists. The objective of this research is to examine the disaggrements between the structuralists and accommodationists, the two main branches of Post Keynesian theory, and to discuss these disagreements in terms of the Minsky's financial instability hypothesis, which sees liquidity preference and leveraged loans as the main reasons for financial instability.
\end{abstract}

\section{Giriș}

Para arzının belirlenme mekanizması ekonomistler tarafından uzun zamandır tartışılmakla birlikte, son yıllarda paranın içselliği sorunu ve likidite tercihleri arasındaki ilişskinin de önemi sorgulanmaya başlanmıştır. Keynes'in likidite tercihine ilişkin açıklaması tüm ekonomik kararların temel belirsizlik koşullarında alındığ görüşüne dayanır ve bu belirsizlik para tutma arzusunun sebebidir. Serbest piyasa ekonomisinde piyasa aktörleri, tam istihdam koşullarından biri olan tam bilgiye sahip değildir ve bu nedenle, iktisadi kararların çoğu belirsizlik altında alınır ve bu kararların şekillenmesinde asıl faktör insanların “hayvansal içgüdüleri”dir. Yine Keynes, Genel Teori'de

\footnotetext{
*Sorumlu yazar/Corresponding author.

e-posta: dicleozdemir@mu.edu.tr
} 
para arzının merkez bankalarının kontrolü altında dışsal olarak belirlendiğini varsayar. Esasen gerek Keynesyen ve gerek Monetarist yaklaşım, paranın dişsal olduğu konusunda hemfikirdir. Keynes'in, Genel İstihdam, Faiz ve Para Teorisi'nde para arzının merkez bankası tarafindan tam olarak kontrol edildiğini açıkça kabul ettiği bilinmektedir. $\mathrm{Bu}$ nedenle, Keynes'in Genel Teori'deki görüşünün dikeyist (verticalist) olarak karakterize edilebileceği de ayrı bir tartışma konusudur (Carvalho, 2013). Keynes, benzer şekilde, Likidite Tercihi Teorisi'nde de belirttiği üzere, faiz oranlarının para otoritesi tarafindan likidite arz ve talebini dengede tutmak amacı ile belirlendiğini öne sürer.

Post Keynesyen teori ise John Maynard Keynes fikrinin bir uzantısı olarak Keynesyen ekonomik düşünce okulunun daha güncellenmiş bir yansıması olarak kabul edilir. Modern ekonomik düşünce ve politikaya yeni bir boyut kazandıran Post Keynesyen iktisat, para arzının içselliğini, belirsizliği, işsizlik oranının azaltılmasında etkin talebin önemini ve neoklasik genel denge modellerinin reddedilmesini öncelikli olarak ele alır. (Vernengo \& Rochon, 2001). Özellikle para arz eğrisinin eğimi ve paranın içselliği ile likidite tercihi teorisinin uygunluğu Post Keynesyenler arasında önemli bir tartışma konusudur. Kaldor, Moore, Lavoie gibi iktisatçıların öncülük ettiği "uyumcu (horizontalists/accommodationists)" görüş, para arzının sadece krediye dayalı olduğunu, para otoritesinin faiz oranını belirlediğini ve artan banka kredileri nedeniyle rezerv talebindeki artışın kaçınılmaz olacağını ileri sürer (Kaldor, 1970; Moore, 1988; Lavoie, 1992). Uyumcu yaklaşım, kredi para arzının faiz oranına sonsuz esnekliğini de varsayar. Bu yaklaşım 1970'lerde geliştirilmiş ve pek çok iktisatçı tarafından desteklenmiştir. Özellikle Kaldor ve Moore para arzının sadece krediye dayalı olduğunu, para otoritesinin faiz oranını belirlediğini, artan banka kredileri nedeniyle rezerv talebindeki artışı karşılamak zorunda olduklarını ve para arzındaki artışın merkez bankaları tarafindan kontrol edilemeyeceğini ileri sürer (Pollin, 1991). Uyumcu Post Keynesyenlerin aksine, Minsky, Rousseau, Dow, Sawyer, Wray gibi "yapısalcı (Structuralists)" iktisatçılar para arzının, kredi talebi ve parasal otoritelerden etkilendiğini kabul etmekle birlikte para arzının, bankaların varlık ve borç yönetimine de bağlı olduğunu iddia ederler (Minsky,1982; Rousseau, 1985; Wray, 1990; Dow, 1997; Sawyer, 2003). Bunun nedeni, merkez bankalarının artan rezerv talebini karşılayamaması durumunda türev araçlar gibi finansal yenilikler ile bu talebi karşılayabilme durumudur (Palley, 2001). Dahası, para otoritesi para talebindeki herhangi bir artışa uyum sağlamayı reddetse bile, bankalar kendi girişimleri ile bu talep artışını kısmen karşılayabilirler (Lavoie, 1986). Piyasa güçleri için gecelik faiz oranını belirlemek mümkün değildir, çünkü rezerv talebi tamamen esnek değildir; rezervlerdeki eksiklik ya da fazlalık faiz oranlarında yapılacak değişikliklerle gideriemez. Yapısalcı yaklaşım, paranın içsel olması durumunda, likidite tercihlerinin bir anlam ifade etmediğini düşünmektedir (Dow, 1997; Sawyer, 1996; Wray, 2007).

Her iki yaklaşım da paranın banka kredilerinden yaratıldığını öne sürer, ancak banka kredi arzının tamamen mi yoksa kısmen mi kredilere olan talep tarafindan belirlendiğini konusunda ayrılığa düşer. Gerçekten de, Post Keynesyen teori, içsel para yaklaşımına dikkat çekse de, iktisat teorisine getirdikleri asıl yenilik, paranın içselliğinin banka kredileri açısından analizidir. Finansal yeniliklerin yaygınlaşması ve finansal araçların çeşitlenmesi sonucu, borçlanma talebi arttığında, bankalar sahip oldukları rezerv miktarından endişe etmeden daha fazla kredi ve banka mevduatı yaratabilmektedirler. Bu, "kredi parası" kavramının, sabit kaldıraç oranına gerek duyulmadan kullanılması olarak düşünülebilir.

Kaldor ve Moore para arzının içsel olarak belirlendiğini ileri sürmelerinin yanında, faiz oranının, merkez bankası tarafından dişsal olarak belirlendiğini öne sürer. Bu görüşün aksine, Minsky, sıkı para politikasının etkin olduğu kısa dönemde finansal yeniliklerden bağımsız bir şekilde oluşan faiz oranındaki bir artışın etkisine ve yine uzun dönemde finansal yeniliklerden kaynaklanan paranın yüksek dolaşım hızına sahip olduğu saiki ile para politikasının etkisiz kalması durumuna dikkat çeker (Mollo, 1999). Bu nedenle, likidite tercihi güçlü ve faiz oranı yüksek olduğu dönemlerde, bankalar, piyasanın likidite ihtiyacını karşılayamayacak, kredi arzı düşecek ve finansal istikrarsızlık yaşanacaktır. Minsky'e göre, yapısal değişikliklerin, merkez bankası tarafından herhangi bir kısıtlama olmadığı duruma kıyasla borç verme kapasitesinde aynı orana artışa yol açma durumu vardır. Ancak uyumculara göre faiz oranı piyasa mekanizması yani ne tasarruf oranı ne de para arz ve talebi tarafindan belirlenmez. Nominal faiz oranı, merkez bankası tarafindan belirlendiği için dışsaldır. Diğer bir ifade ile faiz oranı, iç ve dış ekonomik koşullara göre dışsal olarak belirlenir (Lavoie, 1992; Moore, 1988). Uyumcuların aksine yapısalcılar ise kredi talebinin tam olarak karşılanması durumunun söz konusu olamayabileceği ve bu nedenle de faiz oranının içsel kaynaklı olarak değişebileceğini ifade eder (Palley, 1997).

$\mathrm{Bu}$ tartışmalar esasen finansal kırılganlık tanımında faiz oranlarının belirlenme sürecinin önemini ortaya koymaktadır. Sonuç olarak, gerek uyumcu Post Keynesyen yaklaşım gerekse yapısalcı Post Keynesyen yaklaşım banka kredisini para ile eş olarak görseler de banka kredisi arzının tamamen ya da k1smen kredi talebi tarafindan belirlenip belirlenmediği konusunda hemfikir değildirler. $\mathrm{Bu}$ çalışmada, paranın içselliğine istinaden, söz konusu Post Keynesyen teorinin iki ana kolunu oluşturan uyumcular ve yapısalcılar arasındaki görüş ayrılıkları, likidite tercihi ve kaldıraçlı kredileri finansal krizlerin ana kaynağı olarak gören Minsky’nin finansal istikrarsızlık hipotezi ile birlikte incelenecektir.

\section{Post Keynesyen Görüşte Paranın İçselliği ve Likidite Tercihi}

Likidite tercih teorisi, diğer bir ifade ile para tahsisi teorisi, paranın içselliği çerçevesinde düşünülebilir. Likit varlık şeklinde tutulan para, likidite talebine her türlü cevap verebilir ve belirsizlik ortamlarında kendisinden beklenen görevi yerine getirebilir. Likidite tercihi teorisi, PostKeynesyen teorinin de ana görüşlerini doğrular; para arzı içseldir, para arz ve talebinin işlevleri birbirlerinden bağımsız değildir ve kısa vadeli faiz oranı dışsaldır (Rochon, 1999a).

Likidite tercih teorisinde paranın talebini açıklamak için ifade edilen diğer güdüler, paranın yaratılması ve üretim 
süreci hakkında hiçbir açıklama getirmezken, Post Keynesyenler için finans güdüsü ile para talebi, tek başına para yaratmanın temeli olan kredi talebini ve firmalar ile bankalar arasındaki kredi ilişkilerini de açıklar. Örneğin Earley'nin belirttiği gibi, borçlanma ve borç verme hacmi, kredi davranışı ile belirlenen içsel davranışa bağlı temel finansal değişkendir (Earley, 1994). Esasen Post Keynesyen görüşün tüm taraftarları, paranın içselliğini kabul etseler de, Uyumcular ve Yapısalcılar arasında bazı görüș ayrılıkları söz konusudur. Uyumcu görüşün öncülerinden olan Moore, merkez bankalarının finansal sistemdeki istikrarı koruma sorumluluğunu yerine getirmek için gerektiği anda bankaların rezerv talebini karşılaması gerektiğini savunur (Moore, 1998). Buna göre, toplam rezervler, bankaların borç verme ve mevduat yaratma faaliyetlerini desteklemek için talep ettikleri rezerv miktarı ile belirlendiği için merkez bankalarının toplam rezervler üzerinde herhangi bir kontrolü söz konusu değildir, ancak merkez bankası, hedefine ulaşmak için, bir para politikası aracı olarak rezerv oranında değişime gidebilir. $\mathrm{Bu}$ nedenledir ki, yapısalcı Post Keynesyen görüşe göre para arz eğrisi tam elastiktir. Diğer taraftan yapısalcı görüş, merkez bankalarının rezervlere ve faiz oranlarına yönelik talebi kısmen karşılayabileceğini ve bu durumun da para arzı fonksiyonunun yukarı doğru eğimli olmasına neden olduğunu savunur.

Post Keynesyen görüşün paranın içsel olarak belirlendiği savı uyarınca, faiz oranlarındaki bir değişimin kredilerin miktarı ve mevduatta bir etkisi olduğu açıktır. Ancak, kapitalist piyasa ekonomisinin gelişmesiyle birlikte, kredi parası ana para biçimine dönüştüğünden itibarı para (fiat money) olarak adlandırılan ve ödeme aracı olarak değerini yasalardan alan para turu daha az önemli hale gelmiştir ve ticari bankalar tarafından oluşturulan kredi ve diğer kredi mevduat formları bankaların rezerv yaratma sürecinde ana rolü üstlenmeye başlamıştır (Wray, 1992). Esasen Palley, Post Keynesyen teorinin ortaya çıkışının monetarist bir tepki niteliğinde olduğu görüşündedir. 1960'li yıllarda yaygınlaşmaya başlayan bu görüşün teorik iddiaları şu şekilde sıralanabilir (Palley, 2014):

1. Para ile finanse edilmediği sürece para ve maliye politikaları etkisizdir.

2. Para arzı dışsaldır ve merkez bankaları tarafından kontrol edilir.

3. Enflasyon sadece para arzındaki büyümeden kaynaklanmaktadır.

4. Merkez bankaları ekonomik istikrarı teşvik etmek için basit bir para arzı büyüme kuralı benimsemelidir.

Sonuç itibarı ile Post Keynesyen teoriye göre paranın içselliği görüşü uyarınca parasal bileşenlerdeki bütün dalgalanmaların nedeni içseldir. Makroekonomik bozulmaların sebebinin merkez bankalarının yetersiz ya da yanlış politikalar izlemesinden kaynaklandığını öne süren Monetarist görüşün aksine Palley, piyasa aksaklıkları ve parasal bileşenler arasında olası bir korelasyonun nedensel olmadığını belirtmiştir.

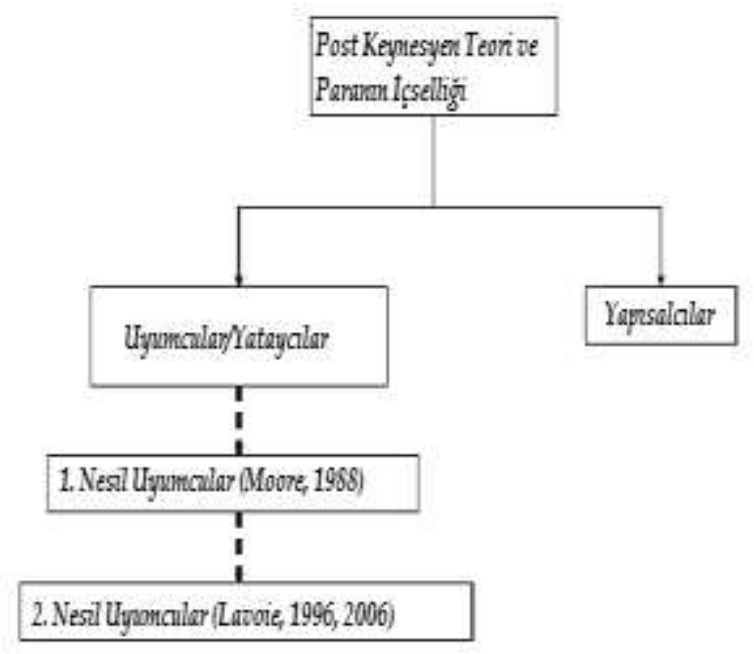

\section{Kaynak: Palley (2017)}

Palley’e göre uyumcular (bkz. Moore, 1988), Keynesyen para teorisinin kalıcı bakış açılarını aşırı derecede sadeleştirme eğilimi göstererek, Post Keynesyenler arasında önemli bir ayrılık ve gereksiz kafa karışıklığına neden olmuştur. Örneğin Moore, likidite tercih teorisini, para talebinin varlığını ve faiz oranlarının içselliğini reddeder. Halbuki daha sonraki uyumcular (bkz. Lavoie, 1996, 2006) likidite tercih teorisini ve faiz oranlarının içselliğini tam olarak kabul ederek, uyumcuların ve yapısalcıların önemli ölçüde yakınlaşmasına katkıda bulunmuştur (Palley, 2017). Palley ayrıca paranın içselliği nedeni ile Monetarist yaklaşımla yürütülecek para politikalarının başarısızlıkla sonuçlanacağını da öne sürer. İş döngülerinin ve finansal istikrarsızlıkların meydana gelmesinde para arzında içsel kaynaklı dalgalanmaların önemli rolü olmasına rağmen Post Keynesyen para teorisinin dinamik sonuçları yeterince geliştirilemediğini de ifade eden Palley, Post Keynesyen para teorisinin güncel literatüre yeteri kadar katk1 sağlayamamasının sebebinin de bu olduğunu savunur (Palley, 2001). Bu bağlamda içsel para teorisinin araştırılması için uyumcu ve yapısalcı yaklaşımlar ve bu teoride likidite tercihlerinin rolü üzerinde durulmasında fayda vardır.

\section{Paranın İçselliği Üzerine Görüş Ayrılıkları}

Kaldor (1970, 1982, 1985), Lavoie (1986) ve Moore (1988, 1989) tarafindan öncülük edilen uyumcu görüşte, merkez bankası politika faizini belirler ve "son borç veren" (lender of last resort) olarak parasal sistemin likiditesinden ve istikrarından sorumludur. $\mathrm{Bu}$ nedenle, merkez bankası, ticari bankaların sadece kredibilitesi olan borçlulara kredi vermesi koşuluyla, gerekli miktarda merkez bankası parasını tedarik ederek kredi bankalarını ve dolayısıyla ticari bankalar ile mevduatlarını tam olarak karşılamak durumundadır. Ticari bankalar, kredi piyasasında faiz oranını belirleyerek, merkez bankasının taban faiz oranı ve daha sonra kredi riski makul düzeyde olan borçlulara bu oranda kredi sağlar. Bu yaklaşımda, likidite tercihi faiz oranlarının seviyesini değil yapısını belirler (Hein, 2009).

Diğer yandan, Post Keynesyen yapısalcılar, paranın içsel olduğu ve merkez bankasının faiz politikasını bir ekonomi politikası aracı olarak kullandığı görüşünü savunurlar. 
Ancak merkez bankalarının her zaman belirli bir faiz oranında gerekli miktarda merkez bankası parasıyla artan banka kredi talebini karşılayamayacağını ileri sürerler. Bu nedenledir ki ticari bankaların finansal yenilikler yolu ile rezervlerini arttırabilme olanakları söz konusudur ve para ve kredi arz eğrilerinin yukarı eğimli olmasının altında yatan esas neden de budur. Bu noktada ekonomik aktörlerin likidite tercihi, para miktarının ve faiz oranlarının belirlenmesinde önem kazanmaktadır. Ancak yapısalcı görüşün taraftarları uyumcu görüşü likidite tercihi teorisini ihmal ettikleri için eleştiriye tabi tutarlar. Söz konusu eleştirinin odak noktasını, uyumcuların, kredi parasının gereğinden fazla arz edilemeyeceği ve bu nedenle bağımsız bir para talep fonksiyonu olamayacağı varsayımı oluşturur (Goodhart, 1989; Palley, 1991; Arestis \& Howells, 1996; Howells, 1997). Dow (1997), likidite tercih teorisinin Keynesyen para teorisinin temelini oluşturduğunu ve bu durumun yapısalc1 Post Keynesyen görüş ile de örtüştüğünü fakat uyumcu Post Keynesyen görüş ile bu noktada ayrıştığını savunur. Dow, likidite tercih teorisinin faiz oranı üzerindeki etkisini göstermek için kredi arz fonksiyonunun talep fonksiyonundan bağımsız olması gerektiğini de belirtmektedir. Keynesyen para teorisinin esasları likidite tercihi kavramı etrafında dönmektedir ve kredi arzı talep tarafından belirlenmediği sürece, diğer bir ifade ile kredi arzı tamamen bağımsız olduğu sürece, Keynesyen para teorisi geçerliliğini korur. Likidite tercihleri, faiz oranı beklentilerine göre değişir; likidite tercihindeki artış, faiz oranlarında yukarı yönlü bir baskı yaratır ve bu da para arzının bir dereceye kadar kısıtlanması halinde, çıktı ve istihdam üzerinde aşağı yönlü baskı oluşturabilir. Ancak bu durum, para arzı fonksiyonunun faiz oranına göre yukarı doğru bir eğime sahip olduğu sürece geçerlidir; para arz eğrisi yatay pozisyonuna yaklaştıkça güç kaybeder (Dow, 1997).

Piyasa aktörlerinin likidite tercihleri birçok faktör aracılığıyla para arzını etkilemektedir. İlk olarak, portföy yapılarındaki değişiklikler ve beklentiler, şirketlerin kârliliğini etkileyebilmekte ve likidite tercih seviyesi düşük olduğunda, daha fazla nakit para ve varlık için cari mevduatlar değiştirilmek istenecektir. Böyle bir durumda, firmaların yüksek verimliliği, sermaye maliyetlerini kullanmak için daha düşük para taleplerine yol açacaktır. b) Bireysel portföyün büyüklüğündeki değişiklikler ile- eğer likidite tercihleri azalırsa, bireyler, ipotek ve tüketici kredilerini kullanmaya daha eğilimli olacaklardır (Trifonov and Trivonova, 2012). Bununla birlikte, Moore, para arz eğrisinde, piyasalarda yenilikler ve finansal yenilikler sonucu oluşabilecek sağa doğru bir kaymanın dışsal nedenli olacağı görüşündedir. Para arz eğrisinde söz konusu olan bu pozitif eğilimin temel olarak iki sebebi vardır; bunlardan ilki belirsizlik nedeni ile bankacılık sisteminin kredi talebi, diğer ise para otoritesinin sergilediği tutumdur. Dow (1997) bu noktada belirsizliğin en az olduğu bir ortamda bankaların geleneksel araçlarla gerçekleştirdikleri yatırımların niteliksel olarak çeşitlenmesi konusunda aktif rol üstlenebileceğini belirtmiştir. Yine böyle bir ortamda para otoritesinin yaklaşımı da para arzının faiz oranına olan duyarlılığında çok önemli bir faktördür. Burada bankaların rezerv ihtiyaçlarının karşılanmasında parasal tabana ulaşılabilirlik kritik bir önem arz etmektedir. Eğer merkez bankası tarafından uyumcu bir politika izlenmesi söz konusu ise, bankalar kredi arz miktarını faiz oranlarında fazla bir etki yaratmadan arttırabilir. Aksi takdirde bankalar portföylerindeki bono ya da varlıklardan satış yoluyla nakit elde etmek durumundadirlar.

Post Keynesyen teorinin bütün farklı görüşlerinde bankaların kredi faiz oranını belirlemede serbest ancak kredi miktarının kontrolünde etkili olmadığ $\breve{1}_{\text {düşüncesi }}$ hakim olsa da faiz oranlarındaki değişimin ekonomiyi sermaye malları ve dayanıklı tüketim malları için aşağı doğru eğimli bir talep eğrisi boyunca hareket ettirdiği görüşü bazı Keynesyen ve heterodoks görüşlerle uyuşmamaktadır (Hansgen, 2003). Paranın ve kredinin büyüme teorilerine sokulması, parasal sistemde borç dinamiklerine önemli bir rol atfeder. $\mathrm{Bu}$ noktada Keynes'den esinlenen Minsky'nin finansal istikrarsızlık görüşlerine yer vermek faydalı olacaktır.

\section{Minsky'nin Dinamik Teorisi}

Minsky, paranın, gerçek ve beklenen fiyat seviyesinin belirleyicisi olduğu ve reel ekonomiden ayrı bir biçimde dışsal olarak belirlendiği görüşünü reddetmiştir. Minsky’ye göre paranın miktarı içseldir ve bankalar kredi arz edip ihtiyaçları olan rezervleri elde edebilirler. İş döngülerinin son aşamalarında ya da diğer bir ifade ile varlık fiyatlarında oluşan balonlaşma süreçlerinin son dönemlerinde finansal kurumların ve bankaların ödeme taahhütlerinin lehine bir faiz oranı ile karşılaşmaları gittikçe zorlaşır. Firmalar, kısa vadeden ziyade, tahvil ve hisse senedi gibi uzun vadeli finansman seçeneklerini değerlendirmeye başlar. Artan borçlanma sonucu oluşan yüksek risk primi, daha fazla geri ödeme yükümlülüklerine neden olur ve döngünün sonlarına doğru artık söz konusu yükümlülüklerin yerine getirilmesi zorlaşmaya başlar. Özellikle bankalar yeni müşterilerinin kredi taleplerini karşılamaya çalıştıkça büyük ölçekli temerrüde düşme riskleri de artar ve sonuç itibarı ile likiditeye yönelik yoğun talep sonucu ekonomide ve finansal yapıda içsel kaynaklı kırılganlıklar oluşmaya başlar.

Minsky'nin finansal istikrarsızlık hipotezinin temelini özellikle belirsizlik ortamlarında kar ya da yeni yatırımlara oranlara aşırı borçlanmanın gittikçe artması oluşturur. Bu noktada gerek Keynes gerekse Minsky depresyondan kaçışın ya da resesyondan çıkışın tek yolunun makroekonomik istikrar politikaları olduğunu savunur. Tymoigne (2006) Minsky'nin iş döngüsünü altı aşamada tanımlar. "Kriz aşaması" kaldıraçlı kredilerin kullanımının artık tükendiği, balon olarak tabir edilen sürecin ani ve hızlı bir şekilde sonlandığı ve yeniden finansman olanaklarının tamamen tükendiği dönemdir. Sonraki süreç "deflasyon" sürecidir; ekonomi aktörlerinin önceliği varlıkların ve borçların geri ödenme safhasında likiditenin hızlandırılmasıdır. "Stagnasyon" aşamasında ekonomik birimler artık daha bilinçlidir; finansal ve yatırım kararları alınırken öz kaynak ve risk faktörleri göz önünde bulundurulur. "İyileşme" döneminde artık geçmişten ders alınmıştır ve tekrar iyimserlik hakimdir. "Genişleme" safhasında yeniden kaldıraçlı kredilere yöneliş başlar; yeni bir balonlaşmaya yol açacak kredi ve varlık fiyatları artışı süreci hız kazanmıştır. En nihayetinde iş döngüsünün son aşaması olan "patlama" noktasına yaklaşılır. Bu son aşama, ekonominin en yüksek istihdam seviyesinde olduğu ve kaldıraçlı kredilerden en yüksek getirinin sağlandığı dönemdir. Bununla birlikte Minsky "Can 'It' Happen 
Again?” (1982) isimli çalışmasında, 1929 yılındaki borsa çöküşünün, 1933 yılında meydana gelen deflasyonist süreci tetiklediğini, ancak, 1962'deki hisse senedi fiyatlarındaki sert düşüşün benzer bir şekilde deflasyonist bir sürece yol açmadığını savunur ve buna neden olarak da federal bütçenin büyüklüğünün tampon etkisini gösterir: hükümet tarafindan yapılan harcamalar ve vergi gelirlerindeki azalma, üretimde düşüşe ve likit varlıkların artmasına neden olmuştur.

Sonuç olarak Minsky'e göre kapitalist ekonominin davranışsal süreci yatırımların ilerleyişine bağlıdır. Yeni yatırımların finansmanı gelecek dönemlerde elde edilecek karların yeterince yüksek olacağı beklentisi ile yapıldığı müddetçe bugünden yapılan kaldıraçlı borçlanmalarda sakınca görülmez. Yatırımlar arttıkça karlar da artacağından kredi talebindeki artışlar banka ve finansal kurumları daha riskli krediler yaratmaya itecektir. Aslında Minsky’ye göre kredi ile sağlanan finansman kaynakları kapitalist üretim sisteminin esasını temsil etmektedir. Foley (2009), bu durumu, finansal sistemde riskli krediler yaratma isteği arttıkça tüketim ve yatırım harcamalarının da bir şekilde tetikleneceğini ancak bu isteklilik konusunda en ufak bir kırılmanın, finansal sistem içinde daha büyük bir hezeyana yol açabileceğini öne sürer.

\section{Finansal İstikrarsızlık Hipotezi ve Paranın İçselliği}

Genel Teoride likidite tercihi konusu, gönüllü olmayan işsizlik ve etkin talep büyük önem taşımaktadır. Keynes, yatırımlardaki dalgalanmaların, toplam harcamaları etkilemek için çarpan aracılığıyla hareket eden ticaret döngüsü üzerindeki birincil etki olduğunu savunur. Uyumcu Post Keynesciler Lavoie (1985) ve Moore (1988), Genel Teori'nin 17. Maddesinde ifade edilen likidite tercihinin, fiziki ve finansal varlıklar arasındaki kısa vadeli varlık piyasası dengesini etkilediği yönündeki görüşünü reddetmiştir. Moore, ek olarak, Keynes'in kuramının döngüsel bir argümana dayandığını, çünkü para talebi ve faiz oranların gelirle birlikte değiștiğini, böylece gelir değiştikçe faiz oranlarının da değişeceğini ve dolayısıyla daha ileri aşamalarda yatırımları etkileyecek gelir ve faiz oranlarında daha da fazla değişimler meydana gelebileceğini ileri sürmektedir. (Wray, 1992). Moore, Genel Teori'nin çarpan analizini ve "kusurlu" bulduğu likidite tercihini içsel bir para yaklaşımıyla değiştirmeyi tercih ederken; Lavoie, finans güdüsünün Keynesyen notasyonlarını eleştirerek, para arzının para talebini rahatlıkla karşılayabildiği bir sistemde finans güdüsü ile para talebindeki artışların faiz oranlarına baskı yapamayacağını öne sürer.

Esasen Minsky, 1980'lerde Post Keynesyenler tarafindan yeniden canlandırılan "içsel para" yaklaşımını benimsemişti. Günümüzde de çoğu Post Keynesyenler, içsel para ve likidite tercihinin uyumlu olduğu düşüncesindedirler. Bununla birlikte bazı Post Keynesciler de Minsky'nin finansal istikrarsızlık hipotezinin para arzının içselliği argümanı ile tutarsız olduğunu ileri sürer (Wray, 2014). Bu görüşün altında yatan temel neden, Minsky'nin istikrarsızlı hipotezinin sadece modern kapitalist ekonomiye dayandığına inanmalarıdır. Söz konusu Post Keynesyen teorisyenlerine göre Minsky’nin yaklaşımı, sabit miktarlı finansman odaklıdır (hatta bazıları tasarruf odaklı kredilendirilebilir bir fon yaklaşımını benimsiyordu) ve bu da içsel para yaklaşımına ters düşmektedir (Wray, 2014). Özetlemek gerekirse, Minsky'nin teorisi, genel bir teori olarak olmamakla birlikte kurumsal olarak spesifik şekilde benimsenmiştir. Daha az karmaşık bir karaktere sahip ekonomilerde finansal kırılganlıkların gerçekleşmesi zor görünse de bu istikrarsılıkların yaşanmayacağı anlamına da gelmemektedir (Dimitri\&Wray, 1997).

Lavoie ve Seccareccia (2001)' nın eleştirileri de tartışmaya önemli katk1 sağlar niteliktedir; Minsky’nin mikroekonomik modelden makroekonomik bir modele geçişte Kalecki'nin kar denklemini doğru bir şekilde dikkate almadığını savunurlar. Yine Rochon ve Vernengo (2004), Lavoie (2001)'nin Minsky eleştirisini doğru bulmakla birlikte Minsky'nin finansal istikrarsılık hipotezine dair çıkarımlarının, faiz oranının büyüme oranından daha büyük olduğu durumlarda geçerli olabileceğini ileri sürer. Buna göre, Minsky, firmaların, bankaların birikmiş kazançlarının üzerinden borçlandıklarından, bankaların borç/özkaynak oranındaki artışların etkisine dikkat çekerler ve bu da eninde sonunda artan borç/özkaynak oranında kırılganlığa yol açacağını savunurlar. Aynı şekilde, bir ekonominin büyüme oranının (g), faiz oranından (1) daha yüksek olduğu bir rejimde $(\mathrm{g}>\mathrm{i})$, Ponzi durumu söz konusu olamaz çünkü finansal sistem firmaların başlangıç kredilerinin bankalara geri ödemelerini sağlayacak yeterli kardan daha fazlasını yaratma kapasitesine sahip olduğu kabul edilir.

\section{Sonuç}

Bu çalışmada Post Keynesyen para teorisindeki uyumculuk ile yapısalcılık arasındaki tartışma, yine Keynesyen makrodinamikteki likidite tercihi ve Minsky'nin finansal kırılganlık hipotezleri açısından ele alınmaktadır. Post Keynesyen teorinin savunucuları arasında parasal bileşenlerdeki dalgalanmaların sebebine istinaden paranın içselliği konusunda da önemli görüş ayrılıkları söz konusudur. İçsel para arzı varsayımı, Post Keynesyen teorinin en önemli temel varsayımları arasında yer alırken, Minsky geleneğindeki finansal istikrarsızlık kavramının paranın içselliği ve likidite tercihi bağlamında tartışılması Post Keynesyenler için özel bir önem arz eder. Post Keynesyen teoride, bankaların önemi, kapitalist bir kurum olarak paranın yaratılması, dolaştırılması ve güvenilirliğinin sağlanması rollerinden kaynaklanır zira parasal sisteme dayanan bir ekonomide kredi talebi her zaman olacaktır ve kredi hacminden para arzına doğru bir nedensellik olduğu kabul edilir. Likidite tercihi kavramı ise özellikle Post Keynesyen iktisatçılar açısından önemlidir zira piyasa aktörleri kredibilitelerini koruduğu sürece kredi parası yaratılabilir ve para stoku da kredi talefi tarafindan belirlenmiş olacağından, bu özelliği itibarı ile içsel olarak değişen para arzı durumu söz konusudur. Bununla birlikte, Post Keynesyen teorisinin iki farklı görüşü temsil eden "uyumcular" ve "yapısalcılar" arasında süren likidite tercihi teorisinden kaynaklanan farklılaşmanın iyi irdelenmesi gerekmektedir.

Uyumcular, banka kredileri faiz oranının bankacılık sektörü tarafından belirlendiğini ve dişsal olduğunu ancak zaman zaman içsel özellik gösterebildiğini fikrini öne sürerken, likidite tercihi kuramının temelinde yatan ihtiyat saiki ile 
para tutma talebini reddederler. Zira, likidite tercihi teorisi, para stoğunun, arzının merkez bankasının kontrolü altında dışsal ve faiz oranının da içsel olarak belirlendiğini varsayan bir teoridir ve bu da para arzının kredi talebi tarafından belirlendiği bir sistemde kabul edilebilir değildir. Onlara göre, faiz oranı merkez bankaları tarafindan rezerv miktarından bağımsız şekilde dişsal olarak belirlenir. Uyumcuların aksine yapısalcılar, sürekli olarak içsel paranın likidite tercih teorisi ile uyumlu olduğunu ve bankaların kredi verme yeteneğinin bankaların piyasada sağlayabilecekleri fonlamanın maliyeti, miktarı ve yapısı ile sınırlandırıldığı görüşündedirler. Likidite tercihi ve kredi yaratma birbiriyle etkileșime girebilir, çünkü bankaların kredi yaratma kapasiteleri borçlarını "para" olarak kabul ettirme yeteneklerine bağlıdır. Bununla birlikte, yapısalcı görüşün paranın içselliği yaklaşımı ile Minky'nin finansal istikrarsızlık hipotezi arasında da ortak noktalar bulunmaktadır zira finansal yenilikler artan talep karşısında paranın dolaşım hızını arttırarak sıkı para politikasını etkinsizleştirebilecektir.

Sonuç olarak, Minsky’nin çok önceleri öngördüğü gibi finansal sistemin son 20 yıldaki gelişimi, kredi kullanımın özellikle türev araçlar vasıtası ile yaygınlaşması, teknolojik gelişmeler ve para piyasasındaki kurumsal değişimler finansal varlıklara olan talebi hızlandırmış ve piyasa aktörlerinin finansman olanaklarını ve kredi arz-talep piyasasının işleyişini büyük ölçüde kolaylaştırmıştır. Uyumcular için bu durum kredi arzının kolaylaştığı bir dünyada paranın içselliği savını güçlendirirken, yataycılar açısından likidite tercihi savını kuvvetli hale getirmektedir. Diğer bir ifade ile, Post Keynesyen iktisatçılara göre, para arzındaki değişikliklerin asıl nedeni enflasyonist baskıdır; ancak bu baskının ne şekilde ortaya çıkabileceği konusunda görüş ayrılıkları mevcuttur.

\section{Kaynakça}

Arestis, P. and Howells, P. (1996). Theoretical Reflections on Endogenous Money: the Problem with Convenience Lending. Cambridge Journal of Economics, 20(5), 539-551.

Bertocco, G. (2001). Is Kaldor's Theory of Money Supply Endogeneity Still Relevant? Metroeconomica, Volume 52, Issue 1, 95-120.

Carvalho F. C. (2013). Keynes and the endogeneity of money. Review of Keynesian Economics, 1, (4), 431446.

Dow, S. C. (1997). Endogenous money. In: G.C. Harcourt and P.A. Riach (eds). A Second Edition of the General Theory. London: Routledge, 1997, 63-71.

Earley, J.S. (1994). Joseph Schumpeter: a frustated 'creditist. In G. Dymski and R. Pollin (eds), New Perspectives in Monetary Macroeconomics: Explorations in the Tradition of Hyman P. Minsky. Ann Arbor: University of Michigan Press.

Foley, D. (2009). The Anatomy of Financial and Economic Crisis. http://blog.santafe.edu/wpcontent/uploads/2009/05/anatfineconcrisesrev4.pdf

Goodhart, C. (1989). Has Moore become too horizontal? Journal of Post Keynesian Economics, 12(1), 29-34.

Hannsgen, G. (2005). "Minsky’s acceleration channel and the role of money." Journal of Post Keynesian Economics 27: 471-490.

Hein, E. (2009). A Post-Keynesian perspective on "financialisation". IMK Studies 01-2009, IMK at the Hans Boeckler Foundation, Macroeconomic Policy Institute.

Kaldor, N. (1970). The new monetarism. Lloyds Bank Review, 97: 1-7

Kaldor, N. (1982). The Scourge of Monetarism. Oxford: Oxford University Press.

Kaldor, N. (1985). How monetarism failed. Challenge, May-June, 4-13.

Lavoie, M. (1986). Systematic Financial Fragility. Journal of Post Keynesian Economics, Vol. 9, No. 2.

Lavoie, M. (1992). Foundations of Post-Keynesian Economic Analysis. Edward Elgar, England.

Lavoie, M. (1996). Horizontalism, structuralism, liquidity preference and principle of increasing risk. Scottish Journal of Political Economy, 43(3), 275-300

Lavoie, M. (2001). The reflux mechanism in an open economy. In L.-P. Rochon and M. Vernengo (eds), Credit, Growth and the Open Economy: Essays in the Horizontalist Tradition. Cheltenham, UK and Northampton, MA, USA: Edward Elgar, 215-42.

Lavoie M. and Seccareccia M. (2001). Minsky’s financial fragility hypothesis: a missing macroeconomic link?

In R. Bellofiore and P. Ferri (eds.), Financial Fragility and Investment in the Capitalist Economy: the Economic Legacy of Hyman Minsky, Vol. II, Cheltenham: Edward Elgar, 76-96.

Lavoie, M. (2006). Endogenous money: Accommodationist. In P.Arestis and M.Sawyer (eds), $A$ Handbook of Alternative Monetary Economics. Cheltenham, UK: Edward Elgar, 17-34.

Minsky, H. (1982). The Financial Instability Hypothesis: an interpretation of Keynes and an Alternative to Standard Theory. In Inflation, Recession and Economic Policy, Wheatsheaf Books Ltd., Great Britain.

Mollo, Maria de L. R. (1999). The Endogeneity of Money: Post Keynesian and Marxian Concepts Compared. Research in Political Economy, 17, 3-26.

Moore, B. J. (1988). Horizontalists and Verticalists: The Macroeconomics of Credit Money. Cambridge, Cambridge University Press.

Moore, B. J. (1989). On the endogeneity of money once more: Comment. Journal of Post Keynesian Economics, 11(3), 479-87. 
Moore, B. J. (1998). Accommodation to accommodationism: A note. Journal of Post Keynesian Economics, 21(1), 175-78.

Palley, T.I. (1991). The endogenous money supply: consensus and disagreement. Journal of Post Keynesian Economics, vol.13, n.3.

Palley, T.I. (1997). Endogenous Money and the Business Cycle. Journal of Economics, 65, no. 2 , 133-149.

Palley, T.I. (2001). Endogenous Money: What it is and Why it Matters.

http://www.thomaspalley.com/docs/articles/macro_the ory/endogenous_money.pdf

Palley, T.I. (2014). Milton Friedman's economics and political economy: an old Keynesian critique. Working Paper 134, IMK/Macroeconomic Policy Institute, Dusseldorf, Germany, July.

Palley, T.I. (2017). The theory of endogenous money and the LM schedule: prelude to a reconstruction of IS-LM. In Advances in Endogenous Money Analysis, edited by L. P.Rochon and S. Rossi. Cheltenham: Edward Elgar, 88-110

Papadimitriou, D. B. \& Wray, L. R. (1997). The Economic Contributions of Hyman Minsky: Varieties of Capitalism and Institutional Reform. Economics Working Paper Archive wp_217, Levy Economics Institute.

Pollin, R. (1991). Two Theories of Money Supply Endogeneity: some empirical evidence. Journal of Post Keynesian Economics, vol.13, n. 3.

Rochon, L. P. (1999a). The Creation and Circulation of Endogenous Money: A Circuit Dynamique Approach. Journal of Economic Issues, vol. XXXIII, no.1, March

Rochon, L. P. (1999b). Credit, money, and production: an alternative post-Keynesian approach. Edward Elgar publishing.
Rochon, L. P. \& Vernengo, M. (2004). Interest Rates, Effective Demand, and Financial Fragility: Edward Nell and The Trieste Tradition. In Growth, Distribution and Effective Demand: Alternatives to Economic Orthodoxy (Essays in honor of Edward J. Nell, edited by G. Argyrous, M. Forstater, and G. Mongiovi, M. E, Sharpe Inc.

Rousseas, S. (1985). A mark-up theory of bank loan rates. Journal of Post Keynesian Economics, 8, 153-144.

Sawyer, M. C. (1996). Money, finance and interest rates. In: Keynes, Money and the Open Economy: essays in honor of Paul Davidson. Cheltenham: Edward Elgar, 1996

Sawyer, M. (2003). Employer of Last Resort: Could it deliver full employment and price stability. Journal of Economic Issues, 37(4), 881-907.

Trifonov, T. \& Trifonova, V. (2012). Endogenous Money and Central Bank's Control on the Short-Term Interest Rates, DOI: 10.7763/IPEDR. 2012. V54. 18

Tymoigne, E. (2006). The Minskyan System, Part II: Dynamics of the Minskyan Analysis and the Financial Fragility Hypothesis. The Levy Economics Institute Working Paper Collection, Working Paper No. 453

Wray, L. R. (1990). Money and Credit in Capitalist Economies: The Endogenous Money Approach, Edward Elgar, Aldershot.

Wray, R. (1992). Alternative Approaches to Money and Interest Rate. Journal of Economic Issues, vol. xxvi, no.4

Wray, R. (2007). Endogenous Money: Structuralist and Horizontalist. Working Paper No. 512, The Levy Economics Institute and University of MissouriKansas City.

Wray, L. Randall (2014). From the state theory of money to modern money theory: An alternative to economic orthodoxy. Working Paper, Levy Economics Institute, No. 792 

